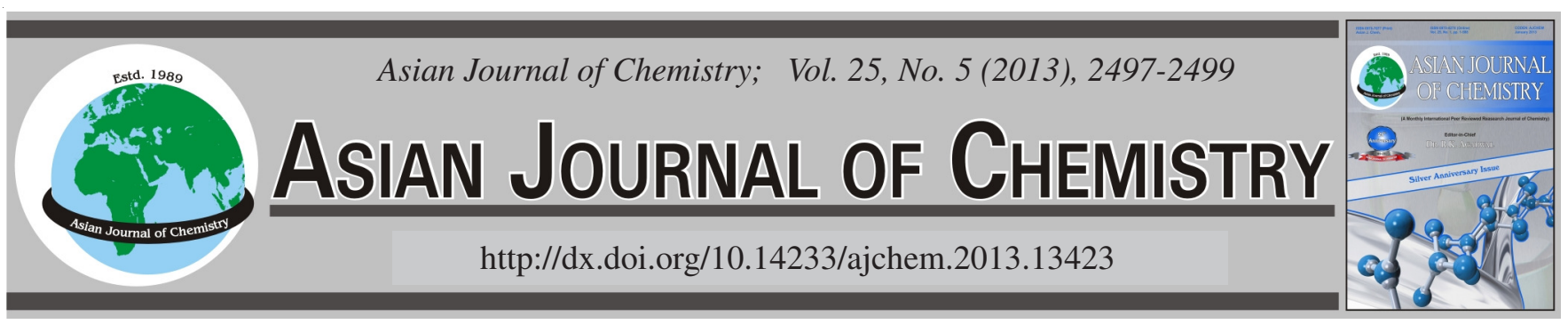

\title{
Durability Studies on Fly Ash Based Geopolymer Mortar Under in Ambient Curing Condition
}

\author{
V. SReevidya*, R. Anuradha, Tini Thomas and R. Venkatasubramani
}

Department of Civil Engineering, Sri Krishna College of Technology, Coimbatore-641 008, India

*Corresponding author: E-mail: sreevidyasankar18@gmail.com

\begin{abstract}
Present paper reports the experimental results of a study conducted to assess the durability of fly ash based geopolymer mortar in adverse environments. In this study, sodium hydroxide and sodium silicate solution were used as alkaline activators. The ratios between solution $\left(\mathrm{NaOH}, \mathrm{Na}_{2} \mathrm{SiO}_{3}\right.$ solution and water) to fly ash were $0.376,0.386,0.396$ and 0.416 by weight. Geopolymer mortar cube specimens of 50 $\mathrm{mm} \times 50 \mathrm{~mm} \times 50 \mathrm{~mm}$ were cast with a ratio of fly ash to sand as $1: 2.5$ by weight. The binder solution consists of a combination of sodium hydroxide and sodium silicate solution in the ratio of 1:2.5. The cubes were cured in ambient condition. The various durability tests like saturated water absorption and acid resistance against $5 \% \mathrm{HCl}$ and $5 \% \mathrm{HNO}_{3}$ were performed on these specimens. The compressive strength after acid resistance was found out and compared with the compressive strength obtained at 28 days. The results obtained from this study indicated that the geopolymer mortar specimens are highly resistant to acids.
\end{abstract}

Key Words: Compressive strength, Durability, Fly ash, Geopolymer mortar, Resistance, Weight loss.

\section{INTRODUCTION}

Portland cement concrete industry has grown astronomically in recent years. It will continue to grow as the result of continuous urban development. However, portland cement concrete possesses problems such as durability and carbon dioxide emission. Many concrete structures have shown serious deterioration, way before their intended service life, especially those constructed in a corrosive environment. Besides good strength, durability is an important property of construction materials. Though Ordinary Portland cement (OPC) is the most commonly used binder in infrastructure construction, its resistance to chemical attacks such as acids and sulphates is of concern. Acid attack has not traditionally attracted much attention, even when cement composites are severely damaged by acids wherein calcium hydroxide is dissolved and the hydrated silicate and aluminium phases are decomposed.

The contribution of Ordinary Portland cement production worldwide to greenhouse gas emission is approximately $7 \%$ of the total greenhouse gas emission to the atmosphere. The production of 1 tonne Ordinary Portland cement consumes 4 GJ energy and produces about 1 tonne of carbon dioxide to the atmosphere ${ }^{1}$. About half of the carbon dioxide emissions from Portland cement production are due to calcination of limestone, while the other half are due to combustion of fossil fuel. In the year 1995, the global production of Ordinary Portland cement was about 1.4 billion tonne, thus emitting about 1.4 billion tonne of carbon dioxide to the atmosphere.

Davidovits ${ }^{2}$ developed Inorganic polymeric materials and coined the term "geopolymer". Geopolymer has the potential to replace ordinary Portland cement and produce fly ash-based geopolymer mortar with excellent physical and mechanical properties. In order to produce geopolymer, low-calcium fly ash needs to be activated by an alkaline solution to produce polymeric Si-O-Al bonds. Geopolymer has the potential to reduce green house emissions by $80 \%$.

Geopolymer is a term covering a class of synthetic aluminosilicate materials with potential use in a number of areas, essentially as a replacement for portland cement and for advanced high-tech composites and ceramic applications. Geopolymer is a novel class of material that is formed by the polymerization of silicon, aluminium and oxygen species to form an amorphous three-dimensional framework structure. As a novel binder, the performance of fly ash based geopolymers is promising; especially in some aggressive situations where portland cement concretes are vulnerable ${ }^{3}$. Geopolymer binders might be a promising alternative in the development of acid resistant concrete ${ }^{4,5}$. Since geopolymers are a novel binder that relies on aluminasilicate rather than calcium silicate hydrate bonds for structural integrity, they have been reported as being acid resistant. 
The present study is aimed to evaluate the response of fly ash based geopolymer mortars to hydrochloric acid and nitric acid in terms of visual appearance, change in weight and compressive strength.

\section{EXPERIMENTAL}

Class F fly ash obtained from Mettur Thermal Power Plant (MTTP) was used in the study. The chemical composition is given in Table-1. The fly ash had a fineness modulus of 7.86 and specific gravity of 2.30 . Fine sand used was local river sand having specific gravity of 2.65 and fineness modulus of 2.25. Laboratory grade sodium hydroxide in pellet form (98 percent purity) with specific gravity of 1.47 and $\mathrm{pH}$ of 14 and sodium silicate solution $\left(\mathrm{Na}_{2} \mathrm{O}=15.9 \%, \mathrm{SiO}_{2}=31.4\right.$ and 52.7 $\%$ water) with silicate modulus $c a .3 .3$ and specific gravity of 1.6 was used. A mixture of Sodium hydroxide and sodium silicate solution in the ratio of 1:2.5 was used to activate the fly ash for producing the geopolymer binder.

TABLE-1 CHEMICAL COMPOSITION OF FLY ASH

\begin{tabular}{ccccccccc} 
Oxides & $\mathrm{SiO}_{2}$ & $\mathrm{Al}_{2} \mathrm{O}_{3}$ & $\mathrm{Fe}_{2} \mathrm{O}_{3}$ & $\mathrm{CaO}$ & $\mathrm{SO}_{3}$ & $\mathrm{Na}_{2} \mathrm{O}$ & $\mathrm{MgO}$ & LOI* \\
\hline
\end{tabular}

\begin{tabular}{llllllllll}
\hline Per cent & 58 & 26.32 & 3.58 & 3.6 & 1.8 & 2 & 1.91 & 2 \\
\hline
\end{tabular}

*Loss on ignition.

Specimen preparation and test procedure: Mortar specimens of $50 \mathrm{~mm}$ cubes were prepared keeping the fly ash to sand ratio as 1:2.5. The solution [water $+\mathrm{NaOH}+\mathrm{Na}_{2} \mathrm{OSiO}_{2}$ ] to fly ash ratios were varied as $0.376,0.386,0.396$ and 0.416 , respectively. The amount of sodium hydroxide and sodium silicate solution were kept constant at 9.6 and $24 \%$ at all mixes. The activator solution is mixed $24 \mathrm{~h}$ prior to the mixing of mortar. Fly ash was first mixed with activator solution for 5 min in a Hobart mixer after which sand was slowly introduced and further mixed for another $5 \mathrm{~min}$ before being vibrated to remove any entrapped air. The mixing was carried out in a room temperature of $25-30{ }^{\circ} \mathrm{C}$. The samples were cured at ambient curing condition. The samples under ambient curing were left at room temperature until tested.

To study the effects of exposure to acidic environment, specimens were immersed in $5 \%$ solution of nitric acid and $5 \%$ solution of hydrochloric acid for a period of 12 weeks, tests being carried out at regular intervals. The volume of acid solution was kept as four times the volume of specimens immersed and stirred every week. The effects of acid on the specimen were constantly monitored through visual inspection, weight change measurements and strength tests during exposure to the acid solution.

\section{RESULTS AND DISCUSSION}

Saturated water absorption: The influence of different ratios of fly ash and sand on the water absorption of geopolymer mortar specimens after 28 days is shown in Fig. 1. From the obtained results it is observed that the percentage of saturated water absorption decreases with increase in w/b ratio. The saturated water absorption percentage is maximum for lowest water binder ratio and minimum for highest ratio.

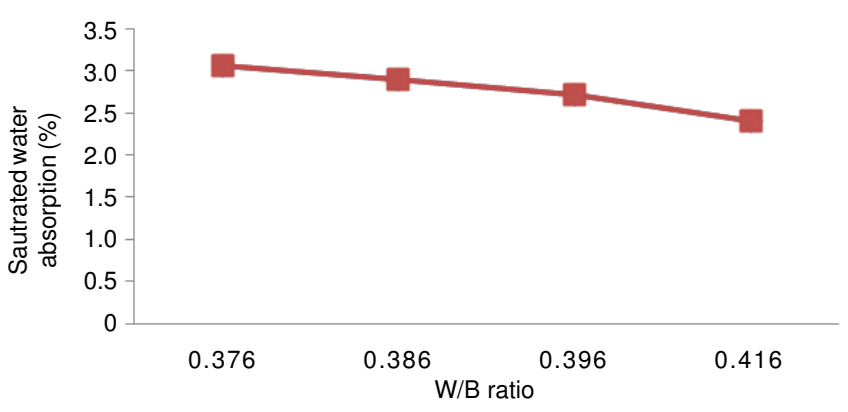

Fig. 1. Saturated water absorption vs. W/B ratio

\section{Acid resistance test}

Visual appearance: Specimens did not exhibit any noticeable colour change and showed no visible signs of deterioration in Hydrochloric acid after 12 weeks of immersion. The specimens were seen to remain structurally intact. The surface became a little softer as the duration of the test progressed but could not be easily scratched with finger nails. The visual inspection of the specimens in nitric acid turned slightly yellowish and even after exposure, specimens were seen to remain structurally intact though surface turned a little softer. The specimens after immersing in nitric acid and hydrochloric acid for 12 weeks are shown in Fig. 2.

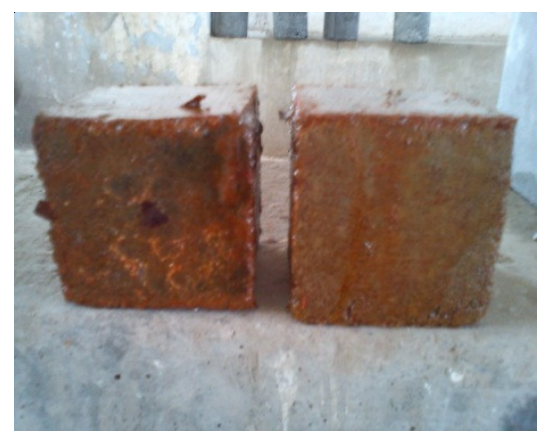

Specimens after immersing in $\mathrm{HNO}_{3}$

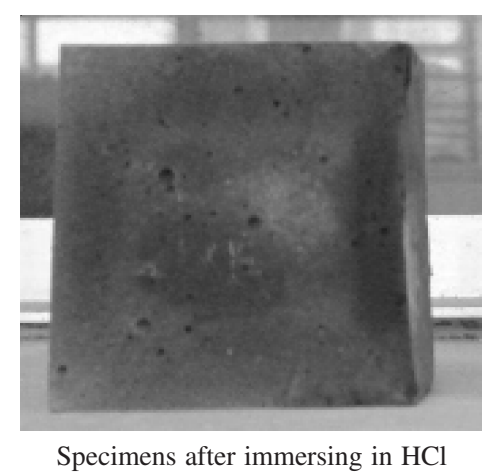

Fig. 2. Specimens after immersing for 12 weeks in $\mathrm{HNO}_{3}$ and $\mathrm{HCl}$

Change in weight: The results of the acid resistance test of various mixes against different acids like nitric acid and hydrochloric acid after 12 weeks are given in Fig. 3.

All the specimens recorded loss in weight over the entire duration of exposure. The loss of weight was observed to be lower in geopolymer mortar specimen when compared with conventional cement mortar. A slight loss of weight was observed in the specimens immersed in $5 \%$ nitric acid and $5 \%$ 


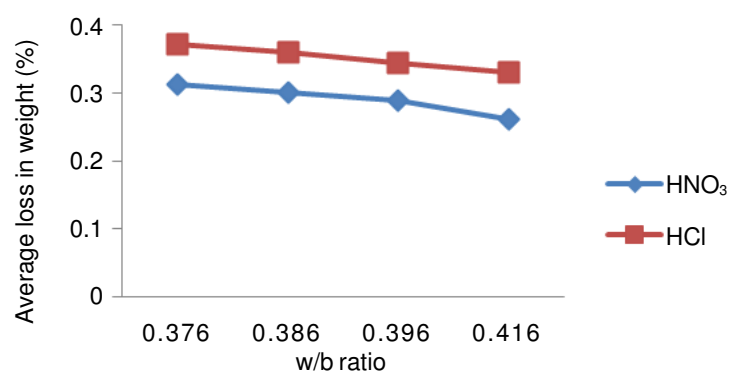

Fig. 3. Average loss in weight versus w/b ratio under ambient curing

hydrochloric acid after 12 weeks. The weight loss in specimens immersed in nitric acid was less compared to those immersed in hydrochloric acid. The weight loss was observed to be gradually decreased with increase in water binder ratio in all the specimens immersed in nitric acid and hydrochloric acid. From the test results it is observed that the average loss in weight is higher for $0.376 \mathrm{w} / \mathrm{b}$ ratio in both specimens immersed in nitric acid and hydrochloric acid under ambient curing.

Change in compressive strength: The compressive strength evolution of geopolymer mortars in nitric acid and hydrochloric acid environment are shown in Fig. 4. The geopolymer mortar specimens showed very little loss in strength. The results showed that the compressive strength after acid resistance test in $\mathrm{HNO}_{3}$ and $\mathrm{HCl}$ under ambient curing is more or less similar to the compressive strength at 28 days.

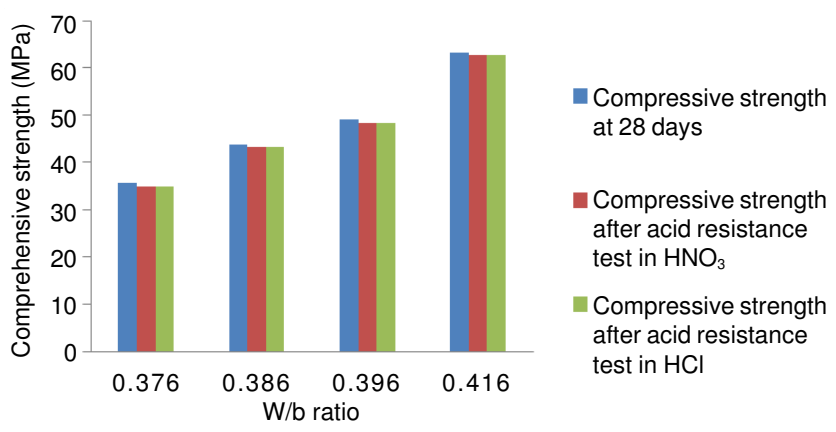

Fig. 4. Variation of compressive strength with $\mathrm{W} / \mathrm{b}$ ratio under ambient curing

\section{Conclusion}

On the basis of findings during the present study, following conclusions are drawn. The saturated water absorption percentage after 28 days curing decreases with increase in water binder ratio. Geopolymer mortar specimens manufactured from fly ash with alkaline activators remained structurally intact and did not show any recognizable change in colour in hydrochloric acid though it turned slightly yellowish in nitric acid solution after 12 weeks of exposure. The loss of weight was observed to be lower in geopolymer mortar specimen when compared with conventional cement mortar. The weight loss in specimens immersed in nitric acid was less compared to those immersed in hydrochloric acid in 1:2.5 FA to sand ratios. The weight loss was observed to be gradually decreased with increase in water binder ratio in all the specimens immersed in nitric acid and hydrochloric acid. Geopolymer mortar specimens showed greater resistance to acid environments when compared with conventional cement mortar specimens. The geopolymer mortar specimens showed little loss in strength.

\section{REFERENCES}

1. P.K. Mehta, ACI Concrete Int., 23, 61 (2001).

2. J. Davidovits, J. Therm. Anal., 37, 1633 (1991).

3. X.J. Song, M. Marosszeky, M. Brungs and R. Munn, Durabilityof Fly ash based Geopolymer Concrete Against Sulphuric Acid Attack, 10 DBMC International Conferences on Durability of Building Materials and Components, Lyon, France, 17-20 April (2005).

4. A Palomo, M.W. Grutzeck and M.T. Blanco, Cement Concrete Res., 29, 1323 (1999).

5. R.N. Thakur and S. Ghosh, Fly Ash based Geopolymer Composites in Proceedings 10th NCB International Seminar on Cement and Building Materials, New Delhi, Vol. 3, pp. 442-451 (2007). 